\title{
Resenha
}

\section{Conexões criativas de empreendedorismo: novas propostas de visibilidade e intervenção social nas periferias do Rio de Janeiro}

Creative connections entrepreneurship: new proposals for visibility and social intervention in the outskirts of Rio de Janeiro

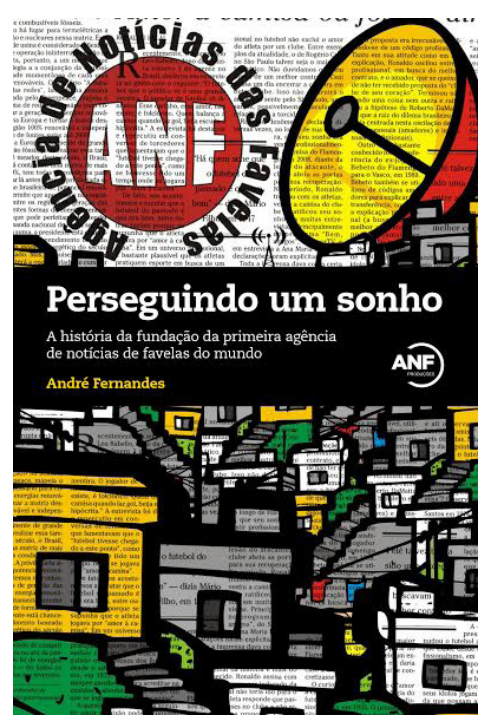

ROSANA MARTINS

Pós-doutora e pesquisadora associada no Centro de Media e Jornalismo - CIMJ,

Universidade Nova de Lisboa - Portugal.

<rosanasantosposse@yahoo.com.br>

\section{RESENHA DE:}

FERNANDES, André.

Perseguindo um sonho. A história da fundação da primeira agência de notícias de favelas do mundo.

Rio de Janeiro: ANF Produções, 2014. 96 p.

Derseguindo um sonho. A história da fundação da primeira agência 1 de notícias de favelas do mundo é o primeiro livro recentemente lançado pela Agência de Notícias das Favelas (ANF), localizada no Rio de Janeiro, e cujo autor e fundador é André Fernandes. A obra propõe 
narrar a história de militância de André Fernandes como missionário nas favelas do Rio de Janeiro, um território marcado pelo estigma da pobreza e da ilegalidade e sob a concentração de uma chamada "classe perigosa". E contra essa generalização, marcada pelo preconceito, indiferença e desrespeito, é que surge a obra lançada em 2014.

O livro se divide em dois prefácios, 15 capítulos e um epílogo. O primeiro prefácio é escrito por Caio Fábio D’ Araújo Filho, ou apenas Caio Fábio, como é mais conhecido. Ele é pastor evangélico, fundador e presidente da Associação Evangélica Brasileira (AEVB) e também psicanalista brasileiro. Caio Fábio destaca a passagem de André Fernandes pelo Jovens com Uma Missão (JOCUM), no Morro Santa Marta (favela localizada entre os bairros de Laranjeiras e Botafogo, na cidade do Rio de Janeiro, no Brasil), com trabalhos realizados na Casa da Paz em Vigário Geral (favela de Vigário Geral, Zona Norte do Rio), em 1993, e na Fábrica de Esperança, em Acari, zona norte do Rio de Janeiro, em 1994; além da expressiva ajuda no início Viva Rio - organização não governamental fundada em 1993 por representantes de vários setores da sociedade civil, como resposta à crescente violência no Rio de Janeiro na época. No prefácio seguinte, escrito por Nilo Batista, fundador do Instituto Carioca de Criminologia, sediado no bairro de Santa Teresa no Rio de Janeiro, ressalta a passagem de André Fernandes como fuzileiro naval, e a incorporação de uma disciplina militar no seu caráter empreendedor de missionário e cristão e que marcou sua percepção social sobre os direitos de cidadania.

Nos capítulos aqui reunidos, o autor revisita o passado de sua infância e que se remetem na relação com seu avô, sendo este seu primeiro entrevistado nos anos de primário, e a lembrança de uma fala que guiou o autor na sua vida de militante e jornalista: "o que é conquistado com dificuldade tem mais sabor na vitória". Foi através do avô que André Fernandes adquiriu a mania de insistir na vida, rompendo os obstáculos, buscando a superação para os desafios. Logo no início do primeiro capítulo 
"O menino do passarinho", o autor fala da conexão entre a história da fundação da primeira agência de notícias das favelas com a sua vida pessoal. André Fernandes não nasceu em nenhuma das favelas das quais trabalhou ou morou. Sua história se remete às redondezas do Morro da Mangueira, zona norte do Rio de Janeiro, onde os pais se conheceram, ainda jovens, e local onde ainda mora sua família. Filho de pai médico e mãe formada em história e em direito, foi no grêmio estudantil pós-ditadura militar, em 1984, na escola pública federal Pedro II, no bairro da Tijuca, zona norte do Rio, que André Fernandes deu seus primeiros passos como ativista social. No entanto, foi a partir do momento que abandonou a carreira de fuzileiro naval para se dedicar a tarefa de missionário cristão na Jovens com Uma Missão (JOCUM) - missão que teve início com o jovem americano Loren Cunningham, em 1960 - que André Fernandes aderiu na luta pela cidadania efetiva na África brasileira (as favelas cariocas).

Trafegando entre becos e vielas, num cenário marcado pela ausência do Estado e pela forte presença do tráfico de drogas e armas de fogo, o autor destaca sua passagem, em fevereiro de 1993, como morador, socorrista e agente de saúde comunitário numa das favelas mais conhecidas do Rio de Janeiro, o Morro Santa Marta, no bairro do Botafogo, na zona sul (cenário para diversos filmes do cinema nacional). "Santa Marta", que intitula o segundo capítulo deste livro, narra o encontro histórico do autor com o "responsável pelo morro", Márcio Amaro dos Santos, conhecido como Marcinho VP (VP ganhou notoriedade no Brasil após "autorizar" as filmagens do clipe de Michael Jackson no Santa Marta, nos anos 90). Por demonstrar preocupações sociais em seu discurso, ao contrário da grande maioria dos outros chefões do tráfico carioca, Marcinho VP acabou se aproximando de intelectuais que passaram a encontrá-lo na clandestinidade. E foi por esse viés que se deu a aproximação de André Fernandes com Marcinho: empréstimos de livros, troca de informações, como numa conversa em que o autor fala a Marcinho VP sobre o Exército Zapatista de Libertação Nacional 
(EZLN) no México, e da luta em prol de se mudar uma dada realidade social, sem o uso de armas de fogo.

Em "Visão Nacional de Evangelização", capítulo terceiro, o autor destaca o papel central desempenhado pelos evangélicos junto aos líderes do tráfico de drogas nas favelas cariocas, que apesar de terem que seguir os códigos de conduta impostos nas favelas como de não divulgar nomes ou apelidos dos chefes do tráfico, possuíam livre trânsito em seus becos e vielas. André chegou a ser nomeado secretário especial da secretaria da Associação Evangélica Brasileira (AEVB), sendo fortemente vinculado às favelas. Participou como coordenador, em 1995, da Campanha "Rio Desarme-se", organizada pelo pastor Caio Fábio (pessoa da qual se tornaria admirador e colaborador em projetos organizados pelo futuro amigo), e coordenada pela AEVB e a ONG Viva Rio, que visava propagar o desarmamento nas favelas do Rio de Janeiro. Citado constantemente pela imprensa como um dos principais mentores e atores do projeto Rio Desarme-se, André Fernandes chegou a ser convidado por governadores de outros estados para falar do tema e suas experiências nas favelas cariocas.

"Casa da Cidadania", nome do quinto capítulo do livro, conta a história da criação da Casa da Cidadania. Situada dentro de cada favela, a casa abrigaria cursos para os moradores visando o entendimento do direito do cidadão. André atuou na Casa da Cidadania até 2002, quando se afastou das atividades de trabalho para participar da criação de sua filha, que acabara de nascer, algo que não foi concretizado com os outros dois primeiros filhos, já que, como o autor mesmo diz, encontrava-se ocupado "em construir um mundo melhor". É nesse mesmo período que André deixa de dar continuidade ao projeto da criação da Agência de Notícias das Favelas (ANF), idealizado em 1997, com lançamento do site em 2001.

Como secretário executivo da ONG Casa da Paz, situada em Vigário Geral, bairro da zona norte do Rio de Janeiro, André Fernandes ganhou respeito dos moradores 
e ficou conhecido por organizar diversas mobilizações de protesto e denúncia pela falta de segurança e violência no local, fato esse que culminou na ameaça de morte que sofreu pelo telefone, exigindo sua retirada do bairro. Esse episódio coincidiria com a fuga do presídio do réu da chacina de Vigário Geral. O capítulo seis, que leva o nome "A Casa da Paz", sugere ao leitor a luta de André Fernandes sempre teve em pensar as favelas cariocas como lugar não de segregação social, mas de sociabilidade, território de paz.

Um fator central para André Fernandes nos seus trabalhos como missionário nas favelas cariocas era a preocupação na defesa e garantia dos direitos dos moradores, ampliando a ideia de cidadania para além dos direitos políticos, e combatendo uma percepção estigmatizada ao mostrar toda a diversidade daquele ambiente. E sendo a cultura um canal para discutir e promover ações inclusivas, surge o Movimento Favelania, título que abre o capítulo sete. Aqui são registradas parcerias importantes do projeto com importantes nomes das periferias brasileiras no mundo da música, como o rapper paulista Mano Brown e o funkerio carioca MC Mister Catra, com uma composição especial para o movimento favelania: "Meu movimento é políticosocial, meu tráfico é cultural". É a cultura reinventando o conceito de favela no reconhecimento da condição de sujeito de direitos e, portanto, à cidade.

Um sonho que tem vez e voz, a Agência de Notícias das Favelas assume sua sede nas dependências da Casa da Cidadania com a proposta de ser uma agência independente da grande mídia e do poder público. "ANF, O Sonho", título do capítulo oito, nasce no dia 08 de janeiro de 2001 com endereço eletrônico (eletrônico www.anf.org.br). A ideia principal era estabelecer uma rede de informações visando a multiplicação de experiências. Ao dar voz aos moradores destas localidades, a ANF destacaria o plano central do seu projeto: a "democratização da informação". Tal democratização passaria para o autor primeiramente pela definição do termo "comunidade", comumente 
utilizado pela grande media e a elite brasileira ao se referir às favelas num processo visando o apagamento das singularidades e diferenças.

Em 2001, André atua como presidente da Associação de Moradores (título do capítulo nove) do Santa Marta. Nessa época, o tráfico de drogas se intensificava na favela, culminando com a derrocada do poder de Marcinho VP e a saída de André, após uma agressão sofrida na favela, da presidência da Associação de Moradores do Santa Marta.

Abusado, é o título do capítulo dez e que faz referência ao título do livro do jornalista brasileiro Caco Barcellos "Abusado - O dono do Morro Santa Marta" e que retrata o banditismo policial no Brasil e as corporações que comandam o tráfico de drogas, e narra a entrada do Comando Vermelho na favela Santa Marta, no bairro de classe média do Botafogo, zona sul do Rio de Janeiro. Marcinho VP é Juliano, personagem do livro de Barcellos. A aproximação entre os dois, Caco e Marcinho, se deveu a André Fernandes. Na época do lançamento do livro, em 2003, André trabalhava como Conselheiro da Comunidade, órgão fiscalizador do Sistema Penitenciário, o que lhe facilitava ter informações sobre o que acontecia nas favelas e nas prisões. Nesse mesmo ano, final de julho, André recebe a notícia sobre a morte de Marcinho VP dentro da prisão Bangu III. Neste período, André Fernandes sofreria novas ameaças, o que o leva a partir para o exílio com sua família.

Em Maringá (título do capítulo onze), no exílio, município brasileiro do Estado do Paraná, região sul do país, o autor ganharia uma bolsa de estudos integral do reitor da universidade do Centro Universitário de Maringá (Cesumar) para estudar jornalismo, como uma contribuição dada pelos trabalhos desempenhados por André nas favelas do Rio. Mesmo com a bolsa de estudos, a vida foi ficando muito dispendiosa para André Fernandes, já que os custos iam de livros, passagens, alimentação, cópias impressas e ainda aumentava a vontade de retornar ao Rio de Janeiro para dar continuidade aos trabalhos da Agência de Notícias das Favelas. 
"De volta à minha cidade", título do capítulo treze, narra a volta ao Rio de Janeiro de André Fernandes e das suas parcerias estabelecidas, como a Universidade do Estado do Rio de Janeiro (UERJ). Surge a logomarca e assim a identidade visual da Agência de Notícias das Favelas. Pelo novo site da ANF, a agência recebe matérias de diferentes partes do mundo, de moradores e não moradores de favelas, de pessoas que compartilham da causa. Com um log in e uma senha fornecida pela ANF, diversos colaboradores publicam seus textos.

A estrutura da ANF, relata o autor no capítulo 15 "Novo Time", se resume num órgão máximo decisório composto por André Fernandes e mais duas pessoas de confiança. A secretaria executiva é composta por três pessoas, secretário executivo, secretário institucional e secretário administrativo, que respondem ao conselho diretor. O conselho fiscal é composto por três membros e dois suplentes. Situada primeiramente nas dependências da casa de André Fernandes, atualmente a redação da ANF encontra-se localizada num espaço cedido pela associação de moradores na favela do Jacarezinho, zona norte do Rio de Janeiro.

O primeiro trabalho aprovado da ANF se deu através da Secretaria de Estado e Cultura do Rio de Janeiro, no final de 2011. O projeto REP - Ritmo e Poesia, executado em 2012, visava atrair a atenção para o espaço sociabilidade e o lazer através da cultura de rua hip-hop para dentro da Jacarezinho, uma das maiores favelas na zona norte do Rio. No início de 2012 veio o projeto Outdoor Social; nesse novo empreendimento ganharam o primeiro cliente: uma operadora de telefonia. $\mathrm{O}$ projeto consistia em colocar publicidade na favela, remunerando cada pessoa envolvida dentro delas, gerando emprego. Até 2014 a voz da ANF atingia não somente as favelas do Rio de Janeiro, mas também São Paulo e Belo Horizonte. Outro projeto é o Guia das Favelas, um levantamento sobre cultura e locais que pudessem ser visitados nas favelas cariocas. O projeto visa ser anual e teve seu primeiro lançamento em julho 
de 2013. No início de 2014, a ANF lançou um aplicativo do Guia das Favelas para celulares.

O livro Perseguindo um sonho não possui um desfecho final, mas sim um processo de desenvolvimento, como relata o autor no epílogo do livro. Aqui, o autor aproveita para fornecer os dados bancários da entidade, endereço, contatos para palestras, contato para aqueles que ao se simpatizar com a causa da democratização da informação nas favelas queiram, em qualquer parte do Brasil e do mundo, se tornar colaborador publicando no portal da ANF.

Sem dúvida, em todas as passagens do livro fica claro ao leitor que o objetivo está em desconstruir estereótipos em torno do que se entende por favela, centrado no processo de valorização das múltiplas vozes presentes naqueles territórios e, capazes de oferecer novas possibilidades de apropriação da produção e circulação do discurso, na maneira como este vem sendo produzido, e no reconhecimento destes novos sujeitos enquanto ativistas interconectados, demandando uma nova escuta social.

Recebido em: 15 ago. 2014

Aceito em: 15 set. 2014

\section{Endereço da autora:}

Rosana Martins <osanasantosposse@yahoo.com.br>

Centro de Investigação Media e Jornalismo

Universidade Nova de Lisboa

Campus de Campolide, 1099-085

Lisboa, Portugal 